\title{
A spatial analysis of childhood stunting and its contextual correlates in India
}

\author{
Rupam Bharti $^{\mathrm{a}}$, Preeti Dhillon ${ }^{\mathrm{b}, *}$, Pralip Kumar Narzary ${ }^{\mathrm{c}}$ \\ ${ }^{a}$ International Institute for Population Sciences, Mumbai, 400088, India \\ ${ }^{\mathrm{b}}$ Department of Mathematical Demography and Statistics, International Institute for Population Sciences, Mumbai, 400088, India \\ ${ }^{\mathrm{c}}$ Department of Development Studies, International Institute for Population Sciences, Mumbai, 400088, India
}

\section{A R T I C L E I N F O}

\section{Keywords:}

Malnutrition

Stunting

Spatial analysis

Temperature

Rainfall

Crop production

\begin{abstract}
A B S T R A C T
Introduction: Despite various programmes aiming to improve the nutritional status of children, nearly $38 \%$ of children under age five are still stunted in India, and there is huge spatial variation across the states.

Objectives: The present study first examines the spatial clustering of childhood stunting and then investigates the contextual determinants including meteorological factors, poverty and crop production affecting childhood stunting.

Methods: The percentage of stunted children under 5 years of age is taken from the district factsheets of National Family Health Survey 2015-16 (NFHS-4). Other data are taken from Census of India (2011) and Ministry of Agriculture and Farmers Welfare. To fulfil the set objectives, the spatial analysis including Moran-I index and spatial regressions models are used.

Results: The spatial analysis shows a high degree of clustering (Moran's I: 0.65) in childhood stunting in districts of India. Extreme temperature of districts reveals a positive association with childhood stunting as nearly $40 \%$ of children from districts with maximum temperature above $40{ }^{\circ} \mathrm{C}$ were stunting. After controlling for socioeconomic factors, spatial regression reveals that a $1{ }^{\circ} \mathrm{C}$ increase in average annual temperature would lead to 0.134 increase in the percentage of stunted children. The study reveals a negative effect of district-level percapita crop production, wealth and education levels on the childhood stunting.

Conclusion: The paper manifests the gigantic variations and clustering in the childhood malnutrition across districts of India. The study recommends to target the districts in hot spot areas, districts with extreme temperature and with low levels of crop production to fight against malnutrition under the umbrella of sustainable development goals.
\end{abstract}

\section{Introduction}

Over the past decade, the momentum of global nutrition issues has been steadily building. In 2012, the World Health Assembly (WHA), adopted the Global Targets including a $40 \%$ reduction in childhood stunting by $2025 .{ }^{1}$ The United Nations Sustainable Development Goals (SDGs) set in 2015 induct the objective of "ending all forms of malnutrition by 2030". While nutrition appears directly in goal number-2, in reality, it is interwoven with all the 17 goals of SDGs. ${ }^{2}$ The first two years of the child's life are crucial for optimum health, brain and physical growth and development. ${ }^{3}$ The good early life health also helps brains to grow and capabilities to develop. ${ }^{4}$ Thus, the concerted focus on reducing stunting reflects an improved understanding of the importance of undernutrition during the most critical period of development in early life and of the long-term consequences extending into adulthood. ${ }^{5}$
Poverty is a main cause of malnourishment because it confines the amount of food available to children causing wasting and a lack of micronutrients value leading to stunting and low weight. ${ }^{6}$ Similarly, a study $^{7}$ exhibited household wealth, and the condition of women was related to both stunting and wasting. Further, overpopulation is a serious problem linked with the competition for food, shelter and medical facilities, and lead to malnutrition amongst children, particularly in the rural areas where access to food and medical facilities were limited. ${ }^{6}$ Also, poverty and malnutrition enhance the risk of infants and children to various kinds of infectious diseases, like diarrhoea and pneumonia, and also increases the possibility of death. ${ }^{8}$ International Food Policy Research Institute (IFPRI) reported that poverty, water, sanitation and hygiene, education, food systems, climate change, social protection, and agriculture all have the vital effect on nutrition outcomes. ${ }^{9}$ Another study conducted by Pathak and Singh $(2009)^{10}$ showed that poverty might not solely be the determinant of child malnutrition. Rather,

\footnotetext{
${ }^{*}$ Corresponding author.

E-mail addresses: rupambharti7@gmail.com (R. Bharti), pdhillon.iips@gmail.com (P. Dhillon), pralipkn@gmail.com (P.K. Narzary).
} 
household environment health risk index which captures the vulnerability of households is found to have a detrimental effect on nutritional status of children, ${ }^{11}$ and the socio-cultural practices had a significant effect on child nutrition. ${ }^{12}$

Underlying contextual drivers-such as food supply, clean water and sanitation, and health care-can contribute a great deal to improving nutrition status. ${ }^{9}$ The availability of safe drinking water and suitable toilet facilities will considerably reduce the levels of severe and moderate malnourishment. ${ }^{13}$ Similarly, a study assertively concludes that for the health of the children, access to potable water, toilet facility and sanitation is crucial. ${ }^{11}$ Contextual correlates such as a low percentage of households connected to the sewerage system in neighbourhood increase longer duration of diarrhoeal episodes among underfives. ${ }^{14}$ Further study by Luke and $\mathrm{Xu}(2011)^{15}$ found the significant effects of neighbourhood on the weight for age at age one.

The contextual factors, such as the extreme temperature prevailing in most of the drought-prone north-eastern districts of Maharashtra, often lead to a severe shortage of water causing poor hygiene and sanitation, thereby promoting disease transmission. ${ }^{13}$ A systematic review article suggested limited literature available on the association of environmental factors with child malnutrition and found that the most of the reviewed articles evident a significant but variable association between rainfall, extreme weather events (floods/droughts), seasonality, and temperature, and childhood stunting at the household level. ${ }^{16}$ Research on Rwanda data suggested that the children who resided in the area with high rainfall were more likely to be stunted. ${ }^{17}$ Another study which integrated NASA's satellite remote sensing data with Demographic and Health Surveys (DHS) data from four West African countries found that the vegetation index had a positive effect on the child survival and nutrition. ${ }^{18}$ Based on 13 African countries data on climate change and socio-economic variables, a study ${ }^{19}$ showed the effect of the decline in seasonal rainfall and the increase in the temperature on the risk of malnourished but this effect could be prevented in regions that increase access to educational resources and basic infrastructure.

A finding from a study in rural Indian setting revealed that children who were exposed to drought in utero or at birth had a higher probability of being underweight and severely underweight, and a higher infant mortality rate. ${ }^{20}$ Another paper found a seasonal pattern in birth weight that was reinforced by the seasonal pattern of diseases. ${ }^{21}$ Food habits and dietary intake and diversity is directly linked with the health and nutrition of the population. Childhood stunting was considered a measure of protein-energy malnutrition. ${ }^{22}$ Poor consumption of nutrition intake is largely determined by access to food, poverty, food habits. A study done in the Indian setting revealed that locally abundant foods were preferred in every region. ${ }^{23}$

The high levels of stunting indicate the continuing large-scale prevalence of chronic malnutrition. ${ }^{24}$ But, despite the progress in disease control, food production, economic, social development and various programmes aiming to reduce malnutrition, India is facing an acute problem of child malnutrition. The prevalence of childhood stunting in India had been at the higher side as about half (48\%) of the children below five were stunted in 2005-06. ${ }^{25}$ Though it had shown remarkable progress, yet remained as high as $38.4 \%$ in $2015-16 .{ }^{26}$ There is also great spatial variation, ranging from just $17.9 \%$ in Kerala to $48 \%$ in Bihar.

It is evident from the existing literature that there is a need to examine the spatial distribution of childhood malnutrition in India at the district-level. Mapping of the variation in child malnutrition can help in improving programs regarding the allocation of limited resources to those districts with high needs of healthcare. Therefore, the present paper attempts to examine spatial clustering of the childhood stunting and its contextual factors including temperature, rainfall, wealth, education and crop production measured at the district level in all 640 districts of India. This study would perhaps be the first attempt to our best knowledge that applies geospatial analysis on childhood stunting
Table 1

Percentage of stunted children under age five in states and India during 2005-06 and 2015-16.

\begin{tabular}{|c|c|c|c|c|c|}
\hline \multirow[t]{2}{*}{ States/UTs } & \multirow{2}{*}{$\begin{array}{l}\text { NFHS-3 } \\
(2005-06) \\
\text { Total }\end{array}$} & \multicolumn{3}{|c|}{ NFHS-4 (2015-16) } & \multirow{2}{*}{$\begin{array}{l}\text { Change } \\
(2005-15)\end{array}$} \\
\hline & & Total & Urban & Rural & \\
\hline Bihar & 55.6 & 48.3 & 39.8 & 49.3 & -7.3 \\
\hline Uttar Pradesh & 56.8 & 46.3 & 37.9 & 48.5 & -10.5 \\
\hline Jharkhand & 49.8 & 45.3 & 33.7 & 48.0 & -4.5 \\
\hline Meghalaya & 55.1 & 43.8 & 36.5 & 45.0 & -11.3 \\
\hline Madhya Pradesh & 50.0 & 42.0 & 37.5 & 43.6 & -8.0 \\
\hline Dadra \& N Haveli & NA & 41.7 & 35.8 & 46.1 & NA \\
\hline Rajasthan & 43.7 & 39.1 & 33 & 40.8 & -4.6 \\
\hline Gujarat & 51.7 & 38.5 & 31.7 & 42.9 & -13.2 \\
\hline Chhattisgarh & 52.9 & 37.6 & 31.6 & 39.2 & -15.3 \\
\hline Assam & 46.5 & 36.4 & 22.3 & 38.0 & -10.1 \\
\hline Karnataka & 43.7 & 36.2 & 32.6 & 38.5 & -7.5 \\
\hline Maharashtra & 46.3 & 34.4 & 29.3 & 38.4 & -11.9 \\
\hline Odisha & 45.0 & 34.1 & 27.2 & 35.3 & -10.9 \\
\hline Haryana & 45.7 & 34.0 & 33.4 & 34.3 & -11.7 \\
\hline Uttarakhand & 44.4 & 33.5 & 32.5 & 34.0 & -10.9 \\
\hline West Bengal & 44.6 & 32.5 & 28.5 & 34.0 & -12.1 \\
\hline NCT of Delhi & 42.2 & 32.3 & 32.4 & 25.1 & -9.9 \\
\hline Andhra Pradesh & 42.7 & 31.4 & 28.3 & 32.5 & -11.3 \\
\hline Sikkim & 38.3 & 29.6 & 22.9 & 32.9 & -8.7 \\
\hline $\begin{array}{l}\text { Arunachal } \\
\text { Pradesh }\end{array}$ & 43.3 & 29.4 & 24 & 30.7 & -13.9 \\
\hline Manipur & 35.6 & 28.9 & 24.1 & 31.4 & -6.7 \\
\hline Chandigarh & NA & 28.7 & NA & NA & NA \\
\hline Nagaland & 38.8 & 28.6 & 22.5 & 30.9 & -10.2 \\
\hline Telangana & NA & 28.1 & 20.9 & 33.3 & NA \\
\hline Mizoram & 39.8 & 28.0 & 22.7 & 33.8 & -11.8 \\
\hline Jammu \& Kashmir & 35.0 & 27.4 & 23 & 28.8 & -7.6 \\
\hline Tamil Nadu & 30.9 & 27.1 & 25.5 & 28.6 & -3.8 \\
\hline Lakshadweep & NA & 27.0 & 27.1 & 25.5 & NA \\
\hline Himachal Pradesh & 38.6 & 26.3 & 21.4 & 26.7 & -12.3 \\
\hline Punjab & 36.7 & 25.7 & 27.6 & 24.5 & -11.0 \\
\hline Tripura & 35.7 & 24.3 & 17.2 & 26.8 & -11.4 \\
\hline Puducherry & NA & 23.7 & 24.7 & 21.1 & NA \\
\hline Daman \& Diu & NA & 23.4 & 21.9 & 27.1 & NA \\
\hline A \& N Island & NA & 23.3 & 17.1 & 27.7 & NA \\
\hline Goa & 25.6 & 20.1 & 18.3 & 23.2 & -5.5 \\
\hline Kerala & 24.5 & 19.7 & 19.8 & 19.5 & -4.8 \\
\hline India & 48.0 & 38.4 & 31.0 & 41.2 & -9.6 \\
\hline
\end{tabular}

Note: NA: Not available.

and relates it with temperature, rainfall, socio-economic and agricultural production variables by including all districts of India.

\section{Methods}

This paper uses the district level indicators from various secondary sources. The percentage of stunted children under five for all 640 districts of India is taken from the district factsheets of National Family Health Survey 2015-16 (NFHS-4). ${ }^{27}$ NFHS-4 is a nationally representative survey that provides childhood stunting status covering all the districts from 37 States and UTs. Other social indicators such as literacy rate, per cent urban, the percentage of scheduled caste and tribes are taken from Census 2011. Further, for calculating household wealth index, household amenities data is taken from Census 2011 house listing files. Rainfall and temperature data for district level is taken from the Town Directory, Census of India, 2011. ${ }^{28}$ There are few districts where data for rainfall was missing, we have replaced those with the state average. Per-capita crop production at the district level is taken from the website of Ministry of Agriculture and Farmers Welfare $(\mathrm{MoAFW})^{29}$ that provides time series data on the area covered, production and yield for about 120 food items for all seasons. Food consumption is directly related to nutrition status, but this information is only available at the state level. Therefore, the study uses per-capita crop production at the district level. 
Table 2

Distribution of districts according to childhood stunting by geographical regions, 2015-16.

\begin{tabular}{|c|c|c|c|c|c|c|c|}
\hline Stunting levels (in \%) & East & West & North & South & North-East & Central & India \\
\hline \multicolumn{8}{|l|}{ Number of Districts } \\
\hline Very low $(<25.00)$ & 7 & 8 & 32 & 34 & 19 & 0 & 100 \\
\hline $\operatorname{Low}(25.01-33)$ & 16 & 14 & 49 & 47 & 29 & 5 & 160 \\
\hline Medium (33.01-41.00) & 25 & 23 & 35 & 16 & 26 & 42 & 167 \\
\hline High (41.01-49.00) & 41 & 20 & 12 & 6 & 9 & 62 & 150 \\
\hline Very high $(>49.01)$ & 22 & 1 & 3 & 4 & 3 & 30 & 63 \\
\hline Total Districts & 111 & 66 & 131 & 107 & 86 & 139 & 640 \\
\hline
\end{tabular}

Note: Regions of India are categorized as per NFHS-3 report. Further, UTs are geographically categorized into regions. The following is the classification of regions-. EAST- Bihar, Jharkhand, Orissa and West Bengal.

WEST - Goa, Gujarat, Maharashtra, Daman \& Diu and Dadra \& Nagar Haveli.

NORTH- Delhi, Haryana, Himachal Pradesh, Jammu \& Kashmir, Punjab, Rajasthan, Uttaranchal and Chandigarh.

SOUTH-Andhra Pradesh, Karnataka, Kerala, Tamil Nadu, Lakshadweep, Puducherry and Andaman \& Nicobar Islands.

NORTH-EAST- Arunachal Pradesh, Assam, Manipur, Meghalaya, Mizoram, Nagaland, Sikkim \& Tripura and.

CENTRAL -Chhattisgarh, Madhya Pradesh \& Uttar Pradesh.

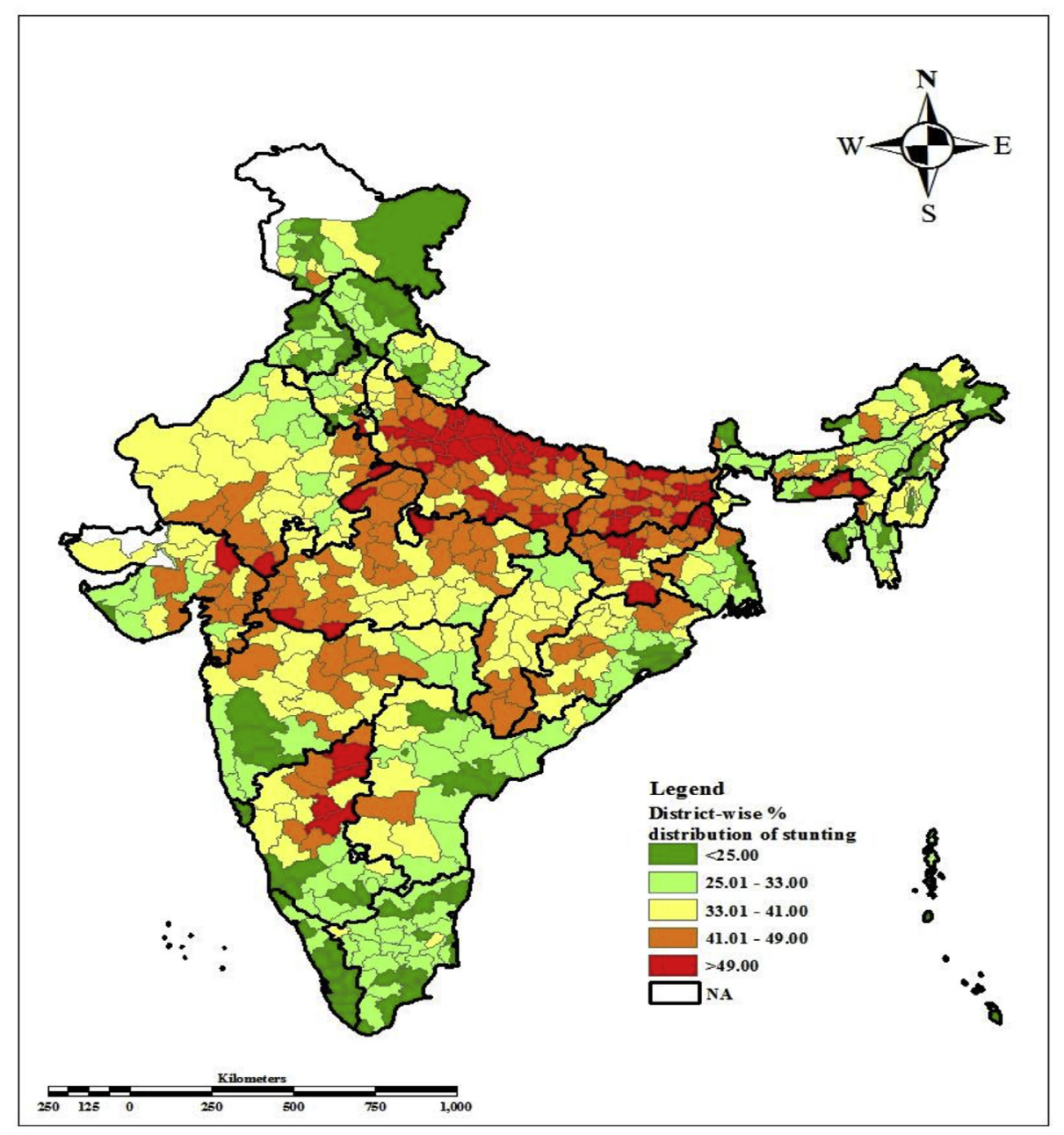

Fig. 1. Geographical distribution of childhood stunting in India, 2015-16.

\section{Measures}

The proportion of stunting is defined as the percentage of children aged 0-59 months old with a height-for-age below minus two standard deviations of the median height-for-age of the reference population. ${ }^{30}$ Stunting is a good indicator of the nutritional status of children for long term growth because it does not vary appreciably by the season of data collection or another short-term factor. ${ }^{31}$ Stunting captures the multiple dimensions of children's health and development, which is considered as the best measure of child health inequality. ${ }^{32}$

\section{Analytical approach}

First, we compile childhood stunting indicator from each state and district factsheets, and then the geographical pattern of the childhood stunting is analyzed. Further, to show the spatial clustering of childhood stunting, the study presents a series of maps using ArcGIS and GeoDa. The computation of spatial autocorrelation requires the 


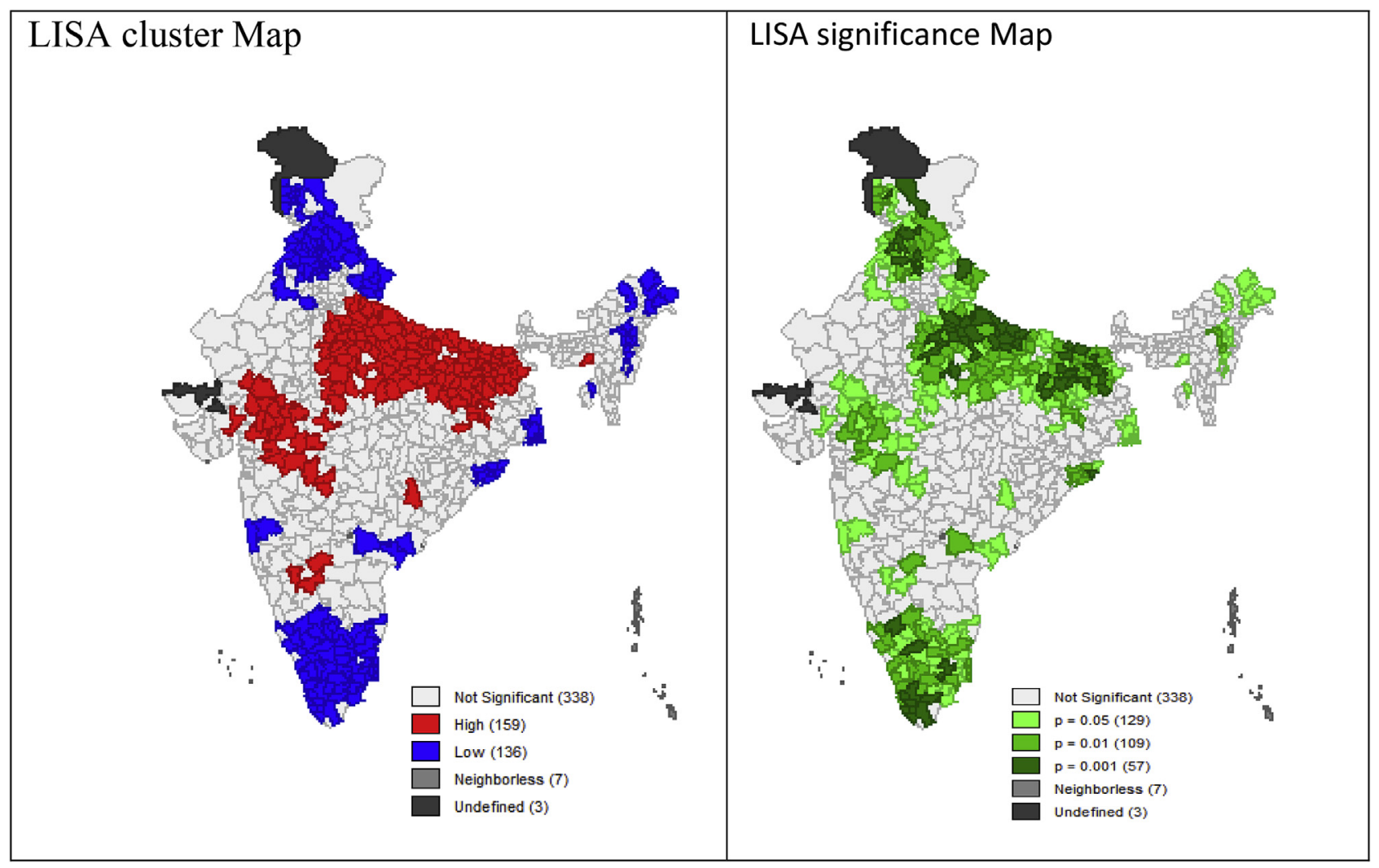

Fig. 2. Spatial clustering of childhood stunting in districts of India, 2015-16.

construction of a matrix known as the spatial weight matrix (W). The matrix can be constructed in various ways which depend on the definition of the neighbourhood. We use spatially contiguous weights (queen's weight) that includes all common points - boundaries and vertices. To manifest the spatial clustering of childhood stunting across districts, we use Moran's I Index and Local Indicators of Spatial Autocorrelation (LISA) to measure the extent of autocorrelation among the neighbourhood districts. The LISA values allow the computation of its similarity with its neighbour districts and also test the significance for each location. In this analysis, five scenarios may take place-cluster with high values (high-high or hot spot), cluster with low values (lowlow or cold spot), outlier in which a high value is surrounded by a low value (high-low), outliers in which a low value is surrounded by a high value (low-high) and no significant local autocorrelation. After confirming that there is significant spatial autocorrelation in stunting across districts of India, such correlation in the dependent variable may lead to correlation among the error terms rendering the Ordinary Least Square (OLS) estimator inappropriate owing to the violation of its assumptions. Therefore, we apply and compare regression models namely ordinary least square (OLS), spatial lag model (SLM) and spatial error model (SEM) to examine the relationship between the outcome variable and a set of predictors.

The spatial OLS regression model takes the form: $y=\alpha+\beta x+\varepsilon$.

The spatial lag model takes the form $y=\alpha+p W y+\beta x+\varepsilon$

The spatial error model takes the form: $y=\alpha+p W y+\beta x+\varepsilon$, with $\varepsilon=\lambda \mathrm{W} \varepsilon+\zeta$

Where y represents the childhood stunting, $\alpha$ is an intercept, $\beta$ is the vector of regression parameters, $\mathrm{x}$ is the matrix of exogenous explanatory variables, $\varepsilon$ is the vector of regression disturbances, Wy the spatial lag term, $r$ is the spatial autoregressive parameter of Wy (which is estimated for the model as a whole), and $\lambda$ is the coefficient of spatially lagged autoregressive errors, We Errors in $\zeta$ are independently distributed, and $\mathrm{W}$ is spatial weight.

\section{Explanatory variables}

The independent variable includes-socio-economic variables compiled from Census of India (2011), namely percentage of urban, the percentage of Muslims, Schedule Caste, Schedule Tribes, per cent literate, improved water, improved sanitation. Further for household income at the district level, a proxy variable that is, wealth index is created using households' amenities and living conditions data from the Census of India, 2011. To construct the index, the principal component analysis (PCA) is adopted. The variable used in PCA includes percentage of households with-different type of materials used for roof, wall, floor, percentage of households with number of rooms, household ownership, drinking water, water source, source of light, latrine, bathroom, household waste, fuel, separate kitchen, bank account and household assets calculated for all districts. First constructed component explains $23 \%$ of variations in data and therefore, is finally considered as wealth score.

The model also includes the climatic variables namely annual average maximum and minimum temperature and annual average rainfall for districts of India. Crop production at the district level may also influence the nutritional status of children. Therefore, we use percapita crop production by type of food items. We categorize different food items into 9 food groups as per indicative crop classification by FAO. ${ }^{33}$ These groups are- 1) Cereals, 2) Vegetables and melons, 3) Fruit and nuts, 4) Oilseed crops, 5) Root/tuber crops with high starch or inulin content, 6) Beverage and spice crops, 7) Leguminous crops, 8) Sugar crops and 9) Other crops. Using district-level population, we calculated per-capita crop production in each group. The reference period for this data is 2011 . 


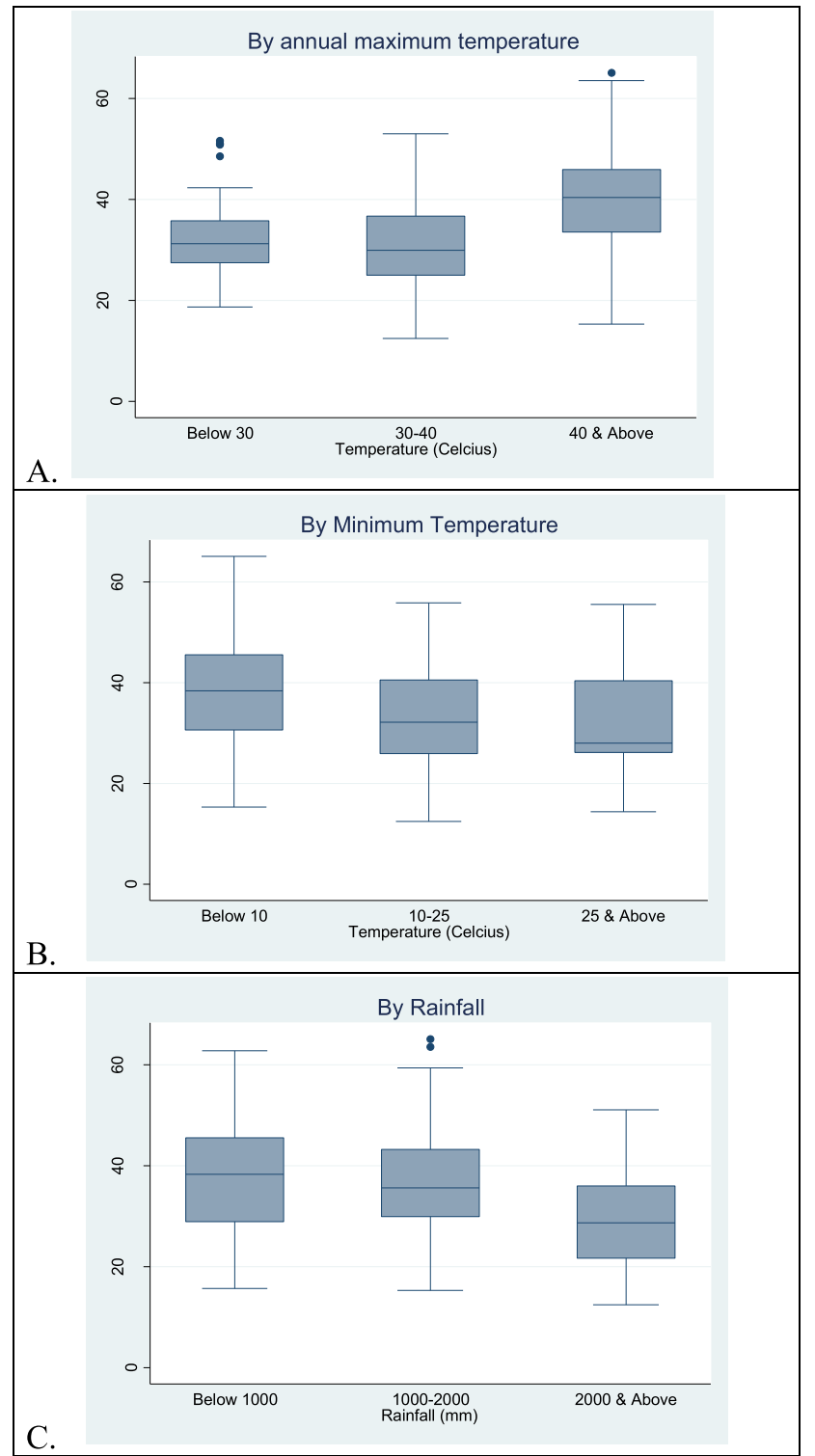

Fig. 3. Box-Plots of childhood stunting according to temperature and rainfall in districts of India, 2015-16.

\section{Results}

The levels of childhood stunting across states from NFHS3(2005-06) and NFHS-4(2015-16) is shown in Table 1. The childhood stunting in India was 48\% in 2005-06 which has declined by nearly ten percentage points and reached $38.4 \%$ in $2015-16$. The stunted children under age five are more in the rural (41.2\%) than in urban India (31\%). In both the rounds of NFHS, the states of Bihar and Uttar Pradesh have the highest percentage of stunted children. Meghalaya which occupied third place in 2005-06 and has marginally improved to occupy fourth place in 2015-16. Chhattisgarh which stood at 4th place in 2005-06 and now improves to 9 th place with whooping $15.3 \%$ point decline. In the same time, Gujarat shifted from 5th place to 8th position. Overall there is a decline in the childhood stunting in all the States and UTs of India. The decline varies from mere 3.8 in Tamil Nadu to as high as $15.3 \%$ point in Chhattisgarh. In 2015-16, along with the union territory of Dadra \& Nagar Haveli, in five states - Madhya Pradesh, Meghalaya, Jharkhand, Uttar Pradesh and Bihar - the percentage of stunted children is $44 \%$ or more.

Table 2 shows the distribution of districts as per childhood stunting levels. It shows that in 63 districts of India the percentage of stunted children is more than $49 \%$ and 213 districts have more than $41 \%$ of stunted children. One of the good pictures is that in 100 districts of India the percentage of stunted children is less than $25 \%$. Further, $66.2 \%$ (92 out of 139) of districts in central, $56.8 \%$ (63 out of 111) of districts in eastern India have more than $41 \%$ stunted children. On the other hand, nearly $16 \%$ of districts in India has less than a quarter of stunted children while this percentage of districts is the highest in South (31.8\%) followed by north India (24.4\%). The geographical distribution of childhood stunting in India (Fig. 1) shows that the highest level of childhood stunting ( $>49 \%$ ) is predominant in the northern part of Uttar Pradesh, scattered in Bihar and Jharkhand, few districts in Rajasthan, Madhya Pradesh, Meghalaya, Gujarat and Andhra Pradesh.

The spatial analysis shows a higher degree of clustering in childhood stunting in districts of India as the Moran's I index is significantly high (0.65). LISA cluster and significant maps in Fig. 2 show total 159 districts in hot spots area, mostly from the central and eastern part of India whereas 136 districts in cold spot area mostly from northern, southern, eastern and north-eastern India. On the other hand, 338 districts have no significant autocorrelation with their neighbouring districts.

The childhood stunting by different levels of temperature and rainfall in India is presented in Fig. 3. On average, about 39.5\% [95\% CI, 38.6, 40.8] of childhood stunting is observed in districts having a maximum (annual) temperature more than $40{ }^{\circ} \mathrm{C}$. Further, the districts with lower than $10^{\circ} \mathrm{C}$ of minimum temperature has also approximately $38.1 \%$ [95\% CI, 37.1, 39.0] of childhood stunting. These findings suggest that extreme levels of temperature have a positive association with childhood stunting. On the other hand, the rainfall levels in districts do not show a strong association with childhood stunting. Though a higher level of rainfall (2000 $\mathrm{mm}$ and above) tends to reduce childhood stunting as shown in panel C of Fig. 3. However, more variation in childhood stunting is visible in districts with a low level of rainfall.

Fig. 4 depicts the bivariate LISA map for childhood stunting with maximum and minimum temperature. Overall, 225 districts have significant clustering of stunting with maximum temperature, out of these districts, 92 are in hot spots while 103 are in cold spots clusters. On the other hand, 253 districts have significant clustering of childhood stunting with minimum temperature level, while 88 districts in hot spots and 143 are in cold spots clusters.

The higher level of spatial clustering measured by Moran'I and LISA confirms the spatial approach would be good while fitting regressions to determine the factors affecting childhood stunting. Table 3 shows the Results of OLS and spatial error model assessing the contextual determinants of childhood stunting. Comparing the regression diagnostics of OLS and two spatial models, the spatial error model (SEM) emerged as the best fit model. Model diagnosis shows a positive value of lamda which is highly significant for the error model.

The OLS Results show a significant effect of district-level socioeconomic variables namely wealth score and per cent literacy in reducing stunting under five. Among both the climatic variables-temperature shows a significant positive effect on stunting. Further, per capita production of cereals, oilseed crops and beverages and spices reduce the risk of childhood stunting. The result of SEM shows a consistent result that among socio-economic groups, per cent literate and wealth index is negatively associated with childhood stunting. The result implies that a $1{ }^{\circ} \mathrm{C}$ increase in average annual temperature (maximum) would lead to 0.134 increase in the percentage of stunted children. Moreover, per-capita crop production in districts particularly oilseed and beverages and spices crops is negatively related to childhood stunting.

\section{Discussion}

Malnutrition among children in India is still considerably high. Nearly $38 \%$ stunting children are reported in $2015-16^{15}$ though an 


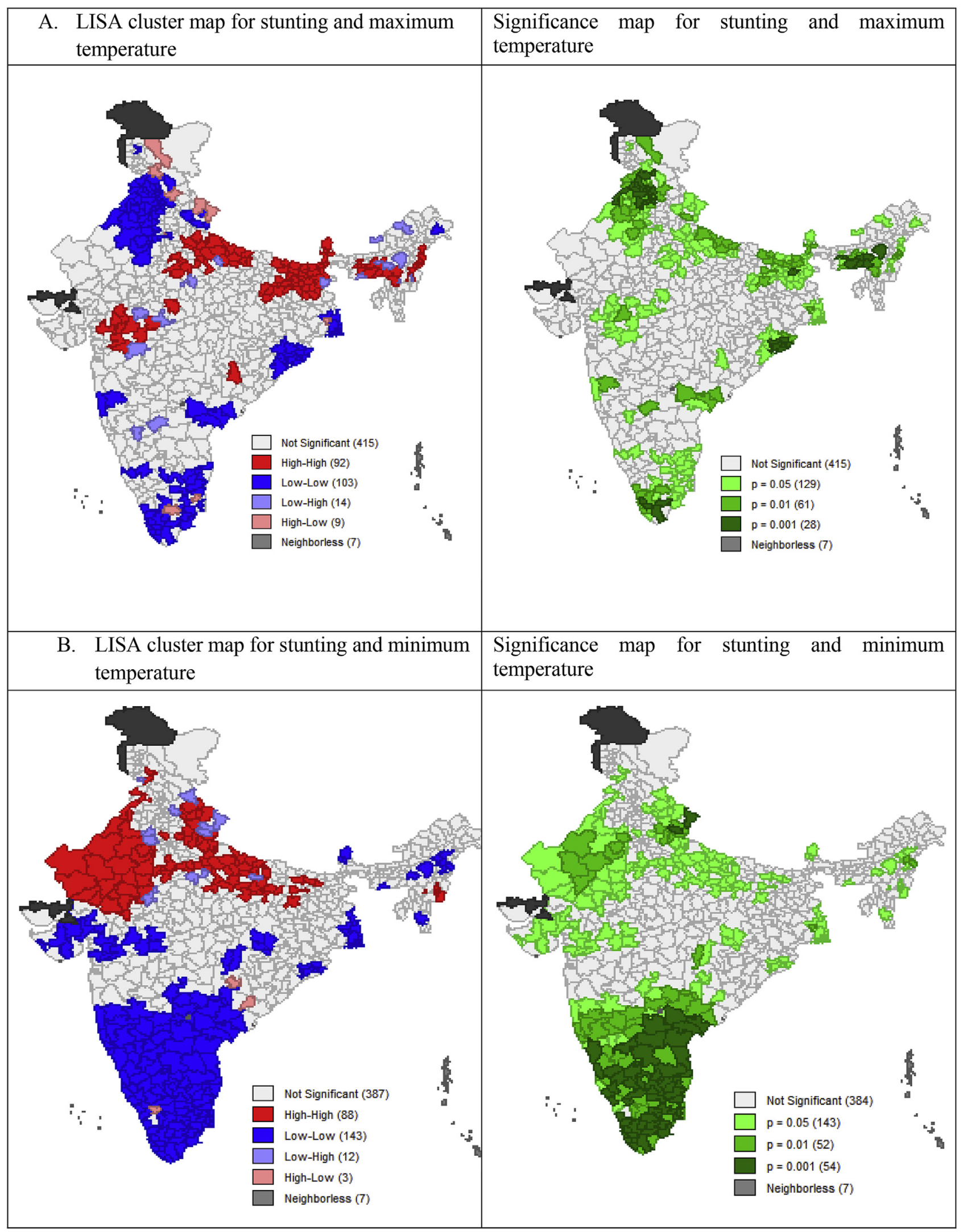

Fig. 4. Spatial clustering of childhood stunting by annual temperature in districts. 
Table 3

Result of OLS model and spatial error model (SEM) assessing the determinants of childhood stunting in India.

\begin{tabular}{|c|c|c|c|c|}
\hline \multirow[t]{2}{*}{ Background variables } & \multicolumn{2}{|l|}{ OLS } & \multicolumn{2}{|l|}{ SEM } \\
\hline & Coefficient & Std. Error & Coefficient & Std. Error \\
\hline$\%$ Urban & $0.098 * * *$ & 0.023 & $0.071^{* * *}$ & 0.024 \\
\hline$\%$ Muslims & -0.014 & 0.019 & 0.038 & 0.023 \\
\hline$\%$ Scheduled Castes/Tribes & -0.001 & 0.016 & 0.014 & 0.017 \\
\hline \% Literate & $-0.228^{* * *}$ & 0.029 & $-0.173^{* * *}$ & 0.036 \\
\hline Wealth score & $-1.286^{* * *}$ & 0.157 & $-1.111^{* * *}$ & 0.212 \\
\hline $\begin{array}{l}\text { Max. temperature (in } \\
\text { Celsius) }\end{array}$ & $0.406^{* * *}$ & 0.069 & $0.134^{*}$ & 0.069 \\
\hline Rainfall (in mm) & 0.001 & 0.001 & 0.000 & 0.001 \\
\hline \multicolumn{5}{|l|}{ Per capita crop production } \\
\hline Cereals & $-0.002^{* *}$ & 0.001 & 0.000 & 0.002 \\
\hline Vegetables and melons & $0.028 * *$ & 0.012 & 0.014 & 0.011 \\
\hline Fruit and nuts & 0.010 & 0.006 & 0.008 & 0.005 \\
\hline Oilseed crops & $-0.022^{*}$ & 0.012 & $-0.039^{* * *}$ & 0.012 \\
\hline $\begin{array}{l}\text { Root/tuber crops with high } \\
\text { starch or inulin } \\
\text { content }\end{array}$ & 0.000 & 0.004 & -0.003 & 0.004 \\
\hline Beverage and spice crops & $-0.050 * * *$ & 0.015 & $-0.028^{* *}$ & 0.012 \\
\hline Leguminous crops & -0.005 & 0.011 & 0.006 & 0.011 \\
\hline \multicolumn{5}{|l|}{ Diagnostic test } \\
\hline Adjusted R-squared & $0.51^{* * *}$ & & & \\
\hline Lagrange multiplier (lag) & $197.785^{* * *}$ & & & \\
\hline Lagrange multiplier (error) & $259.375^{* * *}$ & & & \\
\hline$\Lambda$ & & & $0.697 * * *$ & \\
\hline \multicolumn{5}{|l|}{$\rho$} \\
\hline AIC & 4324.76 & & 4106.24 & \\
\hline Breusch-Pagan test & $32.09 * * *$ & & $37.529 * * *$ & \\
\hline
\end{tabular}

Note: $* * * \mathrm{p}<0.01, * * \mathrm{p}<0.05, * \mathrm{p}<0.10$

appreciable decline is also observed from $48 \%$ in 2005 . Nevertheless, the gigantic geographical differentials are present in child malnutrition. For instance, childhood stunting ranges from $17.9 \%$ in Kerala to $48 \%$ in Bihar. The study shows that one third (213 out of 640) of districts in India comprise more than $41 \%$ childhood stunting. Further, $66.2 \%$ and $56.8 \%$ districts in central and eastern regions respectively have more than $41 \%$ stunted children. A series of spatial clustering maps are developed to investigate whether the stunting among districts are related to the stunting levels of the neighbouring districts or not. The study demonstrates a significantly higher value of Moran I (0.65) that suggests a high level of spatial clustering of childhood stunting in districts. The similar spatial clustering in childhood malnutrition was observed in a recent study. ${ }^{34}$ Earlier studies ${ }^{34-37}$ showed clustering of infant and child mortality and its contextual correlates. In the present paper, bivariate LISA maps highlight a total of 159 hot spots districts mostly from the central and eastern part of India. These districts are highly needed areas where nutrition programmes and interventions should be strengthened.

The present study further identifies the contextual factors measured at the district levels such as extreme temperature, rainfall, socio-economic status and crop production affecting childhood stunting. Nearly, $40 \%$ of children from districts with annual average maximum temperature above $40^{\circ} \mathrm{C}$ and minimum temperature below $10^{\circ} \mathrm{C}$ are stunted. Spatial regressions also suggest a significant positive association between temperature and childhood stunting after controlling for the socio-economic profile of districts. Our attempt is consistent with the findings of another study. ${ }^{13,16}$ However, prior studies in the Indian context, have examined the effects of droughts, not the temperature or rainfall [20 21]. The finding of a positive association between childhood stunting and temperature may be supported by the fact that the weather may affect child health as some diseases are more likely to develop in extreme temperature level. Further, children who frequently have diseases like diarrhoea also consequently suffer from malnutrition. ${ }^{38}$ Moreover, food availability and consumption patterns may also depend on the climatic conditions of the region. The study could not find strong evidence of the effect of average rainfall in districts on childhood stunting. Although we could not take seasonal changes in rainfall that might be a better predictor of under-nutrition as evident in other studies. ${ }^{17}$ The finding that the per capita crop production in districts reduces the childhood stunting manifests that more production of crops provides access to food. It is evident in an earlier study that locally abundant food is preferred in every region of India. ${ }^{23}$ Among socio-economic variables, wealth score and literacy rates of districts are found to be key variables in reducing stunting. However, the effect of other contextual vulnerability variables such as sanitation facility, water sources are shown separately as these variables are included in the construction of wealth score. Further, this paper has not used climatic change variables such as weather variability, drought, or variability in agricultural production by seasons. ${ }^{16,20}$ These linkages should be made in future research by integrating environmental, agricultural and health and demographic data. Nevertheless, the paper finds a vital role of contextual factors-neighbourhood, a higher level of temperature, crop production in districts, district level wealth score and education.

\section{Conclusions}

The findings of the present study are crucial for district level planning for child health. Regional pattern and clustering of indicators used in the study suggest a need to strengthen and continue district focused programmes. Mapping of the variation in child malnutrition can help in improving programs in terms of the allocation of limited resources to those districts with high needs of healthcare. The meteorological factors including extreme temperature are found to be positively associated with stunting levels. The present work further provides the linkages between district level per capita crop production which is negatively related to the stunting. This is a very crucial finding that shows production of crops may increase accessibility and consumption of food in those areas and consequently the low risk of childhood stunting. District level household's wealth index and literacy rates have shown the greatest effect in reducing stunting under five. Finally, by integrating climatic, agricultural, socio-economic status variables measured at the district level, the present paper is able to contribute in filling the research gap in identifying the importance of the contextual correlates and neighbourhood for childhood stunting in India. Estimating the effects of these contextual factors may help in identifying the districts of vulnerability to under-nutrition in India.

\section{Funding}

This research did not receive any specific grant from funding agencies in the public, commercial, or not-for-profit sectors.

\section{Conflict of interest}

We declare that no competing interests exist.

\section{Acknowledgements}

This research received no specific grant from any funding agency, commercial entity or not-for-profit organization. We are thankful to the reviewers from the journal for giving their useful comments for the improvement of this article.

\section{References}

1. International Food Policy Research Institute (IFPRI). Global Nutrition Report 2016: From Promise to Impact: Ending Malnutrition by 2030 Washington, DC 2016; 2016.

2. United Nations System Standing Committee on Nutrition (UNSCN). Nutrition and the Post-2015 Sustainable Development Goals. Geneva: UNSCN; 2014.

3. Sethi V, Bhanot A, Dar S, Parhi RN, Mebrahtu S. Bihar's burden of child stunting a district-wise analysis. Econ Pol Wkly. 2017;52(10). 
4. Coffey D, Deaton A, Drèze J, Spears D, Tarozzi A. Stunting among children, facts and implications. Econ Pol Wkly. 2013;48(34):68-70.

5. United Nations Children's Fund (UNICEF). Improving Child Nutrition, the Achievable Imperative for Global Progress. New York: UNICEF; 2013.

6. Arunkumar N, Hidhayathulla A. Measuring poverty through child malnutrition, a study with special reference to Arumbavur village at Perambalur district. $J$ Econ Financ. 2015;6(2):10-13.

7. Martorell R, Young MF. Patterns of Stunting and wasting: potential explanatory factors. Adv. Nutr. 2012;3:227-233. https://doi.org/10.3945/an.111.001107.

8. Singh A, Pathak PK, Chauhan RK, Pan W. Infant and child mortality in India in the last two decades: a geospatial analysis. PLoS One. 2011;6(11):e26856https://doi.org/ 10.1371/journal.pone.0026856.

9. International Food Policy Research Institute (IFPRI). Global Nutrition Report, Actions and Accountability to Accelerate the World's Progress on Nutrition Washington, DC 2014; 2014.

10. Pathak PK, Singh A. Singh KK, Yadava RC, Pandey Arvind, eds. Geographical Variation in Poverty and Child Malnutrition in India. Population, Poverty and Health: Analytical Approaches. New Delhi, India: Hindustan Publishing Corporation; 2009:183-206.

11. Singh DK, Alagarajan M, Ladusingh L. What explains child malnutrition of indigenous people of Northeast India? PLoS One. 2015;10(6):e0130567https://doi.org/ 10.1371/journal.pone.0130567.

12. Rao GR, Ladusingh L, Pritamjit R. Nutritional status of children in north-east India. Asia Pac Popul J. 2004;19:39-56.

13. Bawdekar M, Ladusingh L. Contextual correlates of child malnutrition in rural Maharashtra. J Biosoc Sci. 2008;40(5) https://doi.org/10.1017/ S0021932008002757.

14. Santos CAST, Strina A, Amorim LD, et al. Individual and contextual determinants of the duration of diarrhoeal episodes in preschool children: a longitudinal study in an urban setting. Epidemiol Infect. 2012;140(4):689-696.

15. Luke $\mathrm{N}, \mathrm{Xu} \mathrm{H}$. Exploring the meaning of context for health Community influences on child health in South India. Demogr Res. 2011;24:345-374.

16. Phalkey RK, Aranda-Jan C, Marx S, Höfle B, Sauerborn R. Systematic review of current efforts to quantify the impacts of climate change on undernutrition. Proc. Natl. Acad. Sci. U.S.A. 2015;112(33):E4522-E4529.

17. Mukabutera A, Forrest JI, Nyirazinyoye L, Marcelin H, Basinga P. Associations of rainfall with childhood under-nutrition in Rwanda: an ecological study using the data from Rwanda meteorology agency and the 2010 demographic and health survey. Asian J. Agric. Food Sci. 2016;4(1):35-45.

18. Johnson K, Brown ME. Environmental risk factors and child nutritional status and survival in a context of climate variability and change. Appl Geogr 2014;54:209-221https://doi.org/10.1016/j.apgeog.2014.08.007.

19. Davenport F, Grace K, Funk C, Shukla S. Child health outcomes in sub-Saharan Africa: a comparison of changes in climate and socio-economic factors. Glob Environ Chang. 2017;46:72-87https://doi.org/10.1016/j.gloenvcha.2017.04.009.

20. Kumar S, Molitor R, Vollmer S. Drought and early child health in rural India. Popul Dev Rev. 2016;42(1):53-68.

21. Crittenden R, Baines J. The seasonal factors influencing child malnutrition on the Nembi plateau, Papua New Guinea. Hum Ecol. 1986;14(2):191-223.
22. Bhutia DT. Protein energy malnutrition in India: the plight of our under five children. J Fam Med Prim Care. 2014;3(1):63-67. https://doi.org/10.4103/2249-4863.130279 PMCID: PMC4005205 PMID: 24791240.

23. Atkin D. Trade, tastes, and nutrition in India. Am Econ Rev. 2013;103(5):1629-1663.

24. Dasgupta R, Sinha D, Yumnam V. Rapid survey of wasting and stunting in children: what's new, what's old and what's the buzz? Indian Pediatr. 2016;53:47-49.

25. International Institute for Population Sciences (IIPS) and IFC. National Family Health Survey (NFHS-4), 2015-16: India. Mumbai: IIPS; 2017.

26. International Institute for Population Sciences (IIPS) and IFC. National Family Health Survey (NFHS-4), 2015-16: District Level Factsheets. Mumbai: IIPS; 2017http://rchiips. org/NFHS/districtfactsheet_NFHS-4.shtml.

27. Office of the Registrar General \& Census Commissioner. India Ministry of Home Affairs Government of India. Town Directory, Census of India; 2011http://censusindia.gov. in/2011 census/censusdata2k11.aspx.

28. Ministry of Agriculture and Farmers Welfare. Govt. of India. Crop Production Statistics Information System 2010-11: District-wise Crop Production Statistics. New Delhi 2010; 2010http://aps.dac.gov.in/APY/Public_Report1.aspx, Accessed date: 6 August 2017.

29. World Health Organization Multicenter Growth Reference Study Group. WHO Child Growth Standards: Length/height-For-Age, Weight-For-Age, Weight-For-Length, WeightFor-Height and Body Mass Index-Forage-Methods and Development. Geneva: World Health Organization; 2006.

30. International Institute for Population Sciences (IIPS) and Macro International. National Family Health Survey (NFHS-3), 2005-06: India. vol. I. Mumbai: IIPS; 2007.

31. World Health Organization. Physical status: the use and interpretation of anthropometry. Report of a WHO Expert Committee Technical Report Series No. 854 Geneva: World Health Organization; 1995.

32. Food and Agriculture Organization of the United Nations. Crops Statistics - Concepts, Definitions and Classifications. http://www.fao.org/economic/the-statisticsdivision-ess/methodology/methodology-systems/crops-statistics-conceptsdefinitions-and-classifications/en/, Accessed date: 9 June 2018.

33. Khan J, Mohanty SK. Spatial heterogeneity and correlates of child malnutrition in districts of India. BMC Public Health. 2018;18:1027. https://doi.org/10.1186/ s12889-018-5873-z.

34. Gupta AK, Ladusingh L, Borkotoky K. Spatial clustering and risk factors of infant mortality: district-level assessment of high focus states in India. Genus. 2016;72:2. https://doi.org/10.1186/s41118-016-0008-9.

35. Kumar C, Singh PK, Rai RK. Under-five mortality in high focus states in India: a district level geospatial analysis. PLoS One. 2012;7(5):e37515https://doi.org/10. 1371/journal.pone.0037515.

36. Ladusingh L, Gupta AK, Yadav A. Ecological context of infant mortality in high-focus states of India. Epidemiol. Health. 2016;38 Article ID: e2016006 https://doi.org/10. 4178/epih/e2016006.

37. Rodrigues M, Bonfim C, Gomes I, Gurgel D, Medeiros Z. Using spatial analysis to identify areas vulnerable to infant mortality. Rev Panam Salud Públic. 2013;34(1):36-40

38. Moore SR, Lima NL, et al. Prolonged episodes of acute diarrhea reduce growth and increase risk of persistent diarrhea in children. Gastroenterology. 2010;139(4):1156-1164. 